Revista Brasileira de Agricultura Irrigada v.11, nº.1, p. 1180 - 1190, 2017

ISSN 1982-7679 (On-line)

Fortaleza, CE, INOVAGRI - http://www.inovagri.org.br

DOI: $10.7127 /$ rbai.v11n100559

Protocolo 559.17 - 30/01/2017 Aprovado em 18/02/2017

\title{
PERCOLAÇÃO DE SOLUTOS EM SOLO FERTIRRIGADO POR GOTEJAMENTO, UTILIZANDO EXTRATORES DE SOLUÇÃO
}

\author{
Elenilson Moreira Franco ${ }^{1}$, Jarbas Honorio de Miranda ${ }^{2}$, Sergio Nascimento Duarte ${ }^{2}$, Nildo \\ da Silva Dias ${ }^{3}$, Clóvis José Bissi Junior ${ }^{1}$, Cleyton dos Santos Fernandes ${ }^{4}$
}

\begin{abstract}
RESUMO
Instalou-se um experimento com o objetivo de avaliar os efeitos de diferentes vazões de gotejadores sobre a distribuição unidimensional dos solutos no perfil de solos, utilizando extratores de solução com cápsula porosa. Os tratamentos utilizados foram obtidos pela combinação de dois solos de texturas contrastantes (arenosa e argilosa) com três vazões de gotejadores (2, 4 e $8 \mathrm{~L} \mathrm{~h}^{-1}$ ) para aplicação de uma única solução fertilizante (Ureia e Cloreto de Potássio), o que caracterizou um arranjo em esquema fatorial $2 \times 3$, com 3 repetições. Os tratamentos foram distribuídos em delineamento experimental inteiramente casualizado com parcelas subdivididas, no qual o perfil foi estratificado em 6 profundidades (cada camada de 10 cm foi considerada subparcela). O ensaio foi conduzido em uma casa de vegetação, na qual foram distribuídos 18 recipientes plásticos, cada um medindo 0,6 e 0,8 m de diâmetro e altura, respectivamente, os quais foram preenchidos com os dois solos. Em cada recipiente foram instalados 6 extratores para obtenção da solução do solo, sendo cada unidade experimental (parcela) constituída por um recipiente. Os resultados evidenciaram que o uso da fertirrigação por gotejamento com elevadas taxas de aplicação promove maior deslocamento dos íons nitrato e potássio em profundidade, sendo este efeito mais intensificado no solo de textura arenosa. Ambos os solos tiveram redução do pH devido à solução de fertilizante aplicada, sendo que os menores valores de $\mathrm{pH}$ foram observados no solo arenoso, havendo redução mais intensa nas camadas superiores. O solo argiloso possui maior capacidade de adsorver os sais aplicados na fertirrigação, o que ocasiona manutenção de menores valores médios da condutividade elétrica de sua solução nas camadas mais profundas.
\end{abstract}

Palavras-chave: distribuição de íons, nitrato, potássio, condutividade elétrica, pH.

\footnotetext{
${ }^{1}$ Doutorando em Irrigação e Drenagem, Escola Superior de Agricultura "Luiz de Queiroz" - ESALQ/USP, e-mail: moreirafranco@gmail.com; cbissijunior@hotmail.com

${ }^{2}$ Professor Doutor da Escola Superior de Agricultura "Luiz de Queiroz" - ESALQ/USP, e-mail: jhmirand@usp.br; snduarte@usp.br

${ }^{3}$ Prof. Doutor da Universidade Federal Rural do Semi-Árido (UFERSA), e-mail: nildo@ufersa.edu.br;

${ }^{4}$ Graduando em Agronomia da Universidade Federal Rural do Semi-Árido (UFERSA), e-mail: cleyton1959@hotmail.com
} 


\title{
SOLUTES PERCOLATION IN SOIL DRIP FERTIGATED USING SOLUTION EXTRACTORS
}

\begin{abstract}
It was installed an experiment in order to evaluate the effect of different drip flow on the unidimensional distribution of solutes in soil profile, using solution extractors with porous capsules. The treatments used were obtained by combination of two contrasting textures soils (sandy and clayey) with three flow drippers $\left(2,4\right.$ and $\left.8 \mathrm{~L} \mathrm{~h}^{-1}\right)$ of an unique fertilizer solution application (Urea and Potassium Chloride), which characterized an arrangemen in factorial scheme with 3 replications. The treatments was distributed in a completely randomized experimental design with split plot, in which the profile was stratified into 6 depths (each layer of $10 \mathrm{~cm}$ was considered subplot). The test was conducted in a greenhouse, in which 18 plastic containers, each measuring 0.6 and $0.8 \mathrm{~m}$ in diameter and height, respectively, were distributed, which were filled with two soils. In each plastic container were installed 6 extractors to obtain the soil solution, being each experimental unit (plot) consisting of a container. The results showed that the use of drip fertigation with high application rates promotes greater displacement of nitrate and potassium ions depth, which had more enhanced effect on sandy texture soils. Both soils had its $\mathrm{pH}$ values of the solution got lower, mainly the sandy one. The clay soil has a greater capacity of adsorving ions, promoting a greater reduction in the electric conductivity of the extracted solutions, mainly in the deeper layers.
\end{abstract}

Keywords: ions distribution, nitrate, potassium, electric conductivity, $\mathrm{pH}$.

\section{INTRODUÇÃO}

A fertirrigação tem-se destacado como uma das tecnologias de maior impacto na produção agrícola, possibilitando a distribuição de nutrientes durante o ciclo da cultura de acordo com a necessidade nutricional das plantas, reduzindo dessa forma os riscos de desperdício de fertilizantes (OLIVEIRA et al., 2011; CAMEIRA et al., 2014). Porém, quando manejada inadequadamente, além de criar condições químicas desfavoráveis no solo, devido à aplicação localizada, a fertirrigação pode ocasionar perda de nutrientes pela percolação hídrica profunda, com consequente aumento no custo de produção e contaminação do lençol freático, comprometendo a qualidade das águas subterrâneas. Segundo Duenhas et al. (2002), essa contaminação do lençol freático é detectada, em geral, pelo aumento da salinidade e da concentração de nitrato, que é um poluente mineral comum nas águas subterrâneas em áreas agrícolas.

Se o excesso de nitrato na solução do solo persistir no intervalo entre cultivos, pode lixiviar com a água das chuvas. O resultado é que, cada vez com mais frequência, se alcançam concentrações desse nutriente das plantas na zona saturada do solo, o que pode afetar a saúde humana e a qualidade ambiental (ARAUZO, 2003; CARVALHO; ZABOT, 2012).

Os extratores de solução no solo providos de cápsulas porosas apresentam-se como uma alternativa promissora para detectar a concentração de íons da solução do solo (SILVA et al., 2013), e sua salinidade. Medeiros et al. (2012) concluíram que os extratores permitem avaliar a concentração do nitrato e do potássio na solução do solo com precisão excelente, assim como sua condutividade elétrica (CE). No entanto, Oliveira et al. (2015) ressaltam que ainda são necessários mais estudos para a disseminação deste método no manejo da fertirrigação, dando ênfase, principalmente, ao estado nutricional das plantas.

A utilização de extratores de solução no solo providos de cápsulas porosas vem se destacando no estudo da dinâmica da água e dos solutos no solo, pois, além de ser um método de baixo custo, reflete as condições reais de umidade e de concentração dos elementos disponíveis às plantas, possibilita a coleta da 
fase líquida diretamente em campo e não é destrutivo, propiciando a repetição da coleta da solução do solo no mesmo local, favorecendo monitoramentos por longos períodos de tempo (DIAS et al., 2005; ; MARQUES et al., 2012; OLIVEIRA et al., 2011; SILVA JÚNIOR et al., 2010; SOUZA, et al., 2013).

Perante o exposto, objetivou-se por meio da utilização de extratores de solução de cápsula porosa, avaliar o efeito da aplicação de diferentes vazões de gotejo sobre a distribuição unidimensional dos solutos formada no perfil do solo, fornecendo assim, um melhor embasamento para práticas de manejo da fertirrigação para sistemas de irrigação por gotejamento.

\section{MATERIAL E MÉTODOS}

O experimento foi instalado em uma casa de vegetação na área experimental do Departamento de Engenharia de Biossistemas da Escola Superior de Agricultura "Luiz de Queiroz" - ESALQ/USP, Piracicaba - SP $\left(22^{\circ}\right.$ 43' 33” de latitude sul e $47^{\circ} 38^{\prime} 00^{\prime}$ ' de longitude oeste, com $511 \mathrm{~m}$ de altitude).

Os tratamentos utilizados foram obtidos pela combinação de dois solos de texturas contrastantes (Latossolo Vermelho Amarelo, fase arenosa, denominado Série "Sertãozinho" solo arenoso e Nitossolo Vermelho, fase argilosa, denominado Série "Luiz de Queiroz" solo argiloso) com três vazões de gotejadores (2 $\mathrm{L} \mathrm{h}^{-1}, 4 \mathrm{~L} \mathrm{~h}^{-1}$ e $8 \mathrm{~L} \mathrm{~h}^{-1}$ ) para a aplicação de uma mesma solução fertilizante (Ureia e Cloreto de potássio), totalizando 6 tratamentos, quais sejam: solo arenoso $+2 \mathrm{~L} \mathrm{~h}^{-1}\left(\mathrm{~T}_{1}\right)$, solo arenoso $+4 \mathrm{~L} \mathrm{~h}^{-1}\left(\mathrm{~T}_{2}\right)$, solo arenoso $+8 \mathrm{~L} \mathrm{~h}^{-1}\left(\mathrm{~T}_{3}\right)$, solo argiloso $+2 \mathrm{~L} \mathrm{~h}^{-1}\left(\mathrm{~T}_{4}\right)$, solo argiloso $+4 \mathrm{~L} \mathrm{~h}^{-1}$ $\left(\mathrm{T}_{5}\right)$ e solo argiloso $+8 \mathrm{~L} \mathrm{~h}^{-1}\left(\mathrm{~T}_{6}\right)$. Estes foram distribuídos em delineamento experimental inteiramente casualizado, com parcelas subdivididas, com 3 repetições; cada parcela foi constituída por um recipiente com solo estratificado em 6 profundidades (camadas de $10 \mathrm{~cm}$ caracterizaram as subparcelas), o que formou um arranjo misto dos tratamentos em esquema fatorial $2 \times 3$.

$\mathrm{Na}$ parte inferior dos recipientes foram feitos 9 furos de $8 \mathrm{~mm}$, os quais permitiram a drenagem do solo quando o volume de solução aplicada excedia a capacidade de armazenamento de cada solo. Uma camada de 0,1 m de brita sob uma manta geotêxtil, foi adicionada à parte inferior interna de cada recipiente, como forma de evitar a obstrução dos furos.

Em seguida, procedeu-se ao preenchimento dos vasos com os solos, que foram previamente destorroados e peneirados em peneira de malha $0,005 \times 0,005 \mathrm{~m}$. Nesta fase, foram coletadas amostras para 0 procedimento da análise granulométrica, no Laboratório Agrotécnico de Piracicaba (PIRASOLO) (Tabela 1) e da análise do extrato da pasta saturada, realizada no Laboratório de Solo e Água do Departamento de Engenharia de Biossistemas da ESALQ/USP (Tabela 2).

Tabela 1. Resultado da análise granulométrica dos solos (Latossolo Vermelho Amarelo- solo arenoso e Nitossolo Vermelho - solo argiloso) utilizados no experimento.

\begin{tabular}{|c|c|c|c|c|c|}
\hline Solo & Argila & Silte & $\begin{array}{l}\text { Areia } \\
\text { Total }\end{array}$ & $\begin{array}{l}\text { Areia } \\
\text { Grossa }\end{array}$ & Areia Fina \\
\hline \multirow{4}{*}{$\begin{array}{l}\text { Arenoso } \\
\text { Argiloso }\end{array}$} & $\begin{array}{l}<0,002 \\
(\mathrm{~mm})\end{array}$ & $\begin{array}{c}0,053-0,002 \\
(\mathrm{~mm})\end{array}$ & & $\begin{array}{c}2,00-0,210 \\
(\mathrm{~mm})\end{array}$ & $\begin{array}{c}0,210-0,053 \\
(\mathrm{~mm})\end{array}$ \\
\hline & ------------.' & 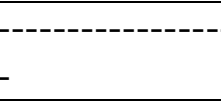 & $\left(\mathrm{g} \mathrm{kg}^{\prime}\right.$ & & --------- \\
\hline & 203 & 27 & 770 & 380 & 390 \\
\hline & 381 & 209 & 410 & 170 & 240 \\
\hline
\end{tabular}

Tabela 2. Resultado da análise do extrato da pasta saturada dos solos (Latossolo Vermelho Amarelosolo arenoso e Nitossolo Vermelho - solo argiloso) utilizados no experimento.

$\begin{array}{lllll}\text { SOLO } & \mathrm{NO}_{3}^{-}\left(\mathrm{mg} \mathrm{L}^{-1}\right) & \mathrm{K}^{+}\left(\mathrm{mg} \mathrm{L}^{-1}\right) & \mathrm{pH} & \mathrm{CE}\left(\mathrm{dS} \mathrm{m}^{-1}\right)\end{array}$




\begin{tabular}{lllll}
\hline Arenoso & 230,20 & 6.70 & 5,50 & 0,35 \\
Argiloso & 145,40 & 5,40 & 5,90 & 0,30 \\
\hline
\end{tabular}

O sistema de irrigação utilizado para aplicação da solução fertilizante (Ureia e cloreto de potássio), era composto por um reservatório de PVC com capacidade para 500 L e 6 linhas de polietileno de $16 \mathrm{~mm}$ de diâmetro nominal. Cada linha, que servia a 3 tratamentos simultaneamente, continha 3 gotejadores que forneciam vazões de 2 , 4 e $8 \mathrm{~L} \mathrm{~h}^{-1}$. Estes operavam a uma pressão de $200 \mathrm{kPa}$, fornecida por uma bomba hidráulica centrífuga, acionada por um motor elétrico de potência igual a $0,5 \mathrm{cv}$, instalada no interior da casa de vegetação.

Os fertilizantes utilizados foram ureia $(45 \% \mathrm{~N})$ e cloreto de potássio $\left(62 \% \mathrm{~K}_{2} \mathrm{O}\right)$ e a ordem de grandeza do volume de solução aplicado em cada irrigação para o gotejador de maior vazão, bem como as dosagens dos fertilizantes, foram pré-definidos com base em estudos sobre as necessidades hídrica e nutricional da cultura da lima ácida 'Tahiti', conforme o calendário de fertirrigação descrito em Machado et al. (2004).

Baseando-se nestes autores, e para permitir o monitoramento da dinâmica dos solutos no solo, foram realizadas 13 fertirrigações sucessivas $(4,40 \mathrm{~L}$ cada, totalizando $57,2 \mathrm{~L}$ ) para os tratamentos com maiores vazões $\left(8 \mathrm{~L} \mathrm{~h}^{-1}\right.$ aplicadas em solos arenoso - $\mathrm{T}_{3}$ e ao solo argiloso $-\mathrm{T}_{6}$ ).

Em função da vazão dos gotejadores, os demais tratamentos receberam, proporcionalmente, 25\% - 1,100 L cada (para vazão $2 \mathrm{~L} \mathrm{~h}^{-1}$ aplicados nos solos arenoso - $\mathrm{T}_{1} \mathrm{e}$ argiloso $-\mathrm{T}_{4}$ ) totalizando $14,3 \mathrm{~L}$, e $50 \%-2,200$ $\mathrm{L}$ cada (para vazão $4 \mathrm{~L} \mathrm{~h}^{-1}$ aplicados nos solos arenoso - $\mathrm{T}_{2}$ e argiloso - $\mathrm{T}_{5}$ ) totalizando $28,6 \mathrm{~L}$ de solução de fertilizantes. Assim, apenas a concentração dos fertilizantes na água de irrigação foi igual em todos os tratamentos (Tabela 3).

Tabela 3. Volume da solução fertilizante em cada fertirrigação, concentração, condutividade elétrica (CE) e $\mathrm{pH}$.

\begin{tabular}{|c|c|c|c|c|c|c|}
\hline \multirow{2}{*}{$\begin{array}{c}\text { Solução } \\
\text { fertilizante }\end{array}$} & \multicolumn{6}{|c|}{ Tratamentos } \\
\hline & $\mathbf{T}_{1}$ & $\mathbf{T}_{2}$ & $\mathbf{T}_{3}$ & $\mathbf{T}_{4}$ & $\mathbf{T}_{5}$ & $\mathbf{T}_{6}$ \\
\hline $\begin{array}{c}\text { Volume aplicado } \\
\text { (L) }\end{array}$ & 1,100 & 2,200 & 4,400 & 1,100 & 2,200 & 4,400 \\
\hline $\begin{array}{c}{[\mathbf{N}]+\underset{\left.\mathbf{L}^{-1}\right)}{\left[\mathbf{K}_{2} \mathbf{O}\right](\mathrm{mg}}} \\
(\mathrm{mg}\end{array}$ & 664,56 & 664,56 & 664,56 & 664,56 & 664,56 & 664,56 \\
\hline $\mathrm{CE}\left(\mathrm{dS} \mathrm{m}^{-1}\right)$ & 2,05 & 2,05 & 2,05 & 2,05 & 2,05 & 2,05 \\
\hline pH & 4,5 & 4,5 & 4,5 & 4,5 & 4,5 & 4,5 \\
\hline
\end{tabular}

No decorrer do experimento, foram aplicadas um total de 13 fertirrigações, com duração de 33 minutos (cada), espaçadas entre si por um intervalo de 4 dias; este período era o necessário para aplicação de vácuo nos extratores de cápsula porosa e posterior extração e análise química da solução do solo.

As variáveis necessárias para traçar o perfil de distribuição do fertilizante no solo foram obtidas por meio da extração e análise periódica da solução do solo, que era realizada por meio de extratores de cápsula porosa. As avaliações foram realizadas após cada fertirrigação e contemplaram um período total de amostragens 52 dias.

Os extratores foram dispostos em semicírculo e instalados a uma distância de aproximadamente 15 centímetros uns dos outros, em profundidades de 10, 20, 30, 40, 50 e 60 centímetros.

Após 12 horas da aplicação da solução fertilizante, e com o auxílio de uma bomba de vácuo, criou-se uma tensão de aproximadamente 80 kPa na câmara interna de cada extrator, para que estes passassem a succionar a solução do solo. Dado o tempo necessário para que se atingisse um equilíbrio do solo com a cápsula do 
extrator de solução (24 horas), prosseguia-se com o processo de recolhimento do conteúdo armazenado nos extratores, utilizando-se para isso uma seringa hospitalar.

As amostras, devidamente identificadas, foram acondicionadas em tubos de acrílico e armazenadas em ambiente refrigerado até o momento das análises.

Para determinação do potássio utilizou-se um fotômetro de chamas e as concentrações de nitrato foram medidas por meio de um espectrofotômetro ultravioleta UV-1203, adotando-se uma técnica descrita por Yang et al. (1998), fundamentada no método colorimétrico. $\mathrm{O} \mathrm{pH}$ e a CE das amostras foram determinadas por um medidor de $\mathrm{pH}$ e um condutivímetro de bancada (Digimed), respectivamente.

A partir dos valores das concentrações de nitrato e potássio da solução do solo, foram elaborados gráficos bidimensionais com a distribuição destes no perfil do solo ao longo do tempo. Para a confecção dos gráficos utilizou-se o software Surfer, na sua versão 7.0 para Windows. Para análise estatística dos dados de concentração de nitrato e de potássio, de $\mathrm{pH}$ e de $\mathrm{CE}$, aplicou-se o procedimento Mixed Procedure do sistema computacional Statistical Analysis System (SAS INSTITUTE, 2003).

\section{RESULTADOS E DISCUSSÃO}

De acordo com a análise de variância apresentada na Tabela 4, a distribuição do íon nitrato no solo foi influenciada por todos os fatores (solo, vazão e profundidade) e suas interações.

Tabela 4. ANOVA para os efeitos da textura do solo, da vazão dos gotejadores, da profundidade do solo e de suas interações sobre a distribuição do íon nitrato ([ $\left.\left.\mathrm{NO}_{3}{ }^{-}\right]\right)$no perfil do solo.

\begin{tabular}{ccccc} 
& \multicolumn{2}{c}{ Grau de Liberdade (GL) } & & Pr $>\mathbf{F}$ \\
\cline { 2 - 4 } Fontes de Variação & Numerador & $\begin{array}{c}\text { Denominad } \\
\text { or }\end{array}$ & F & \\
\hline Solo & 1 & 12 & 192,82 & $<0,0001$ \\
Vazão & 2 & 12 & 137,01 & $<0,0001$ \\
Solo*Vazão & 2 & 12 & 29,45 & $<0,0091$ \\
Profundidade & 5 & 60 & 54,15 & $<0,0001$ \\
Solo* Profundidade & 5 & 60 & 15,27 & $<0,0001$ \\
Vazão* Profundidade & 10 & 60 & 17,22 & $<0,0001$ \\
Solo*Vazão* Profundidade & 10 & 60 & 6,21 & $<0,0001$ \\
\hline
\end{tabular}

Verificou-se que houve diferença entre as concentrações de nitrato no solo, segundo as profundidades e os tipos de solo. Como era esperado, as maiores taxas de aplicação (maiores volumes de solução de fertilizantes aplicados) proporcionaram maior poder de percolação do nitrato; porém, as maiores médias ficaram concentradas nas primeiras camadas, principalmente no caso do solo argiloso. Esta tendência também foi observada para as vazões menores, mas de forma menos clara, o que significa que a percolação do nitrato está diretamente relacionada ao número de volumes de poros que passa por cada camada (MIRANDA et al., 2010) (Tabela 5).

Tabela 5. Médias dos teores de $\mathrm{NO}_{3}{ }^{-}\left(\mathrm{mg} \mathrm{L}^{-1}\right)$ na solução dos solos arenoso e argiloso, nas profundidades 10, 20, 30, 40, 50 e $60 \mathrm{~cm}$, quando submetidos a 13 aplicações de solução de fertirrigação com vazões de 2 , 4 e $8 \mathrm{~L} \mathrm{~h}^{-1}$.

\begin{tabular}{|c|c|c|c|c|}
\hline \multirow[b]{2}{*}{ Solo } & \multirow[b]{2}{*}{$\begin{array}{c}\text { Profundidade } \\
\text { (cm) }\end{array}$} & \multicolumn{3}{|c|}{ Vazão dos gotejadores $\left(\mathrm{L} \mathrm{h}^{-1}\right)$} \\
\hline & & 2 & 4 & 8 \\
\hline renoso & 10 & 938,67 Aa & $959,97 \mathrm{Aa}$ & $807,07 \quad \mathrm{Ac}$ \\
\hline
\end{tabular}


Franco et al.

\begin{tabular}{cccccc} 
& 20 & $692,23 \mathrm{Aba}$ & $972,17 \mathrm{Aa}$ & $769,83 \mathrm{Aa}$ \\
& 30 & $486,90 \mathrm{ABb}$ & $1045,87 \mathrm{Aa}$ & $786,57 \mathrm{Aab}$ \\
& 40 & $446,53 \mathrm{Bb}$ & $664,03 \mathrm{Abab}$ & $1159,20 \mathrm{Aa}$ \\
& 50 & $455,70 \mathrm{Bb}$ & $555,30 \mathrm{Bb}$ & $1189,63 \mathrm{Aa}$ \\
& 60 & $397,90 \mathrm{BCb}$ & $479,30 \mathrm{Bab}$ & $830,63 \mathrm{Aa}$ \\
\hline \multirow{3}{*}{ Argiloso } & 10 & $559,17 \mathrm{Aba}$ & $815,47 \mathrm{Aba}$ & $953,87 \mathrm{Aa}$ \\
& 20 & $225,17 \mathrm{Cb}$ & $934,10 \mathrm{Aba}$ & $1180,53 \mathrm{Aa}$ \\
& 30 & $150,67 \mathrm{Db}$ & $601,67 \mathrm{Aba}$ & $1182,03 \mathrm{Aa}$ \\
& 40 & $161,30 \mathrm{Db}$ & $194,03 \mathrm{Cb}$ & $962,97 \mathrm{Aa}$ \\
& 50 & $159,07 \mathrm{Db}$ & $139,23 \mathrm{Cb}$ & $790,70 \mathrm{Aa}$ \\
& 60 & $168,17 \mathrm{Da}$ & $137,70 \mathrm{Ca}$ & $266,30 \mathrm{Ba}$ \\
\hline
\end{tabular}

Médias seguidas pela mesma letra, minúsculas nas linhas e maiúsculas nas colunas não diferem entre si, pelo teste de Tukey $(\mathrm{P}>0,05)$

Os teores de nitrato encontrados nos tratamentos com o solo arenoso foram maiores do que aqueles encontrados no solo argiloso. Neste primeiro solo $\left(T_{1}, T_{2}\right.$ e $\left.T_{3}\right), \quad$ o comportamento do íon nitrato foi semelhante em todos os tratamentos $(\mathrm{P}>0,05)$, atingindo profundidades elevadas desde a sétima avaliação.

As concentrações do íon nitrato ([$\left.\left[\mathrm{NO}_{3}{ }^{-}\right]\right)$, em $\mathrm{mg} \mathrm{L}^{-1}$, observadas nas soluções extraídas no solo pelos extratores de solução, instalados a diferentes profundidades, para cada tratamento, e denominados de "leituras" (numeradas de 1 a 13), foram plotadas pelo programa "Surfer" (versão 7.0 para Windows), de maneira a permitir-se observar sua distribuição no solo (Figura 1).

Observa-se, em cada coluna, que à medida que se desloca para a direita (leituras posteriores) aparecem isolinhas de maior concentração. Nos tratamentos T1 e T4 (vazão de apenas $2 \mathrm{~L} \mathrm{~h}^{-1}$ ) esse efeito é observado apenas nas camadas mais rasas, devido ao menor volume de solução de fertirrigação aplicado.
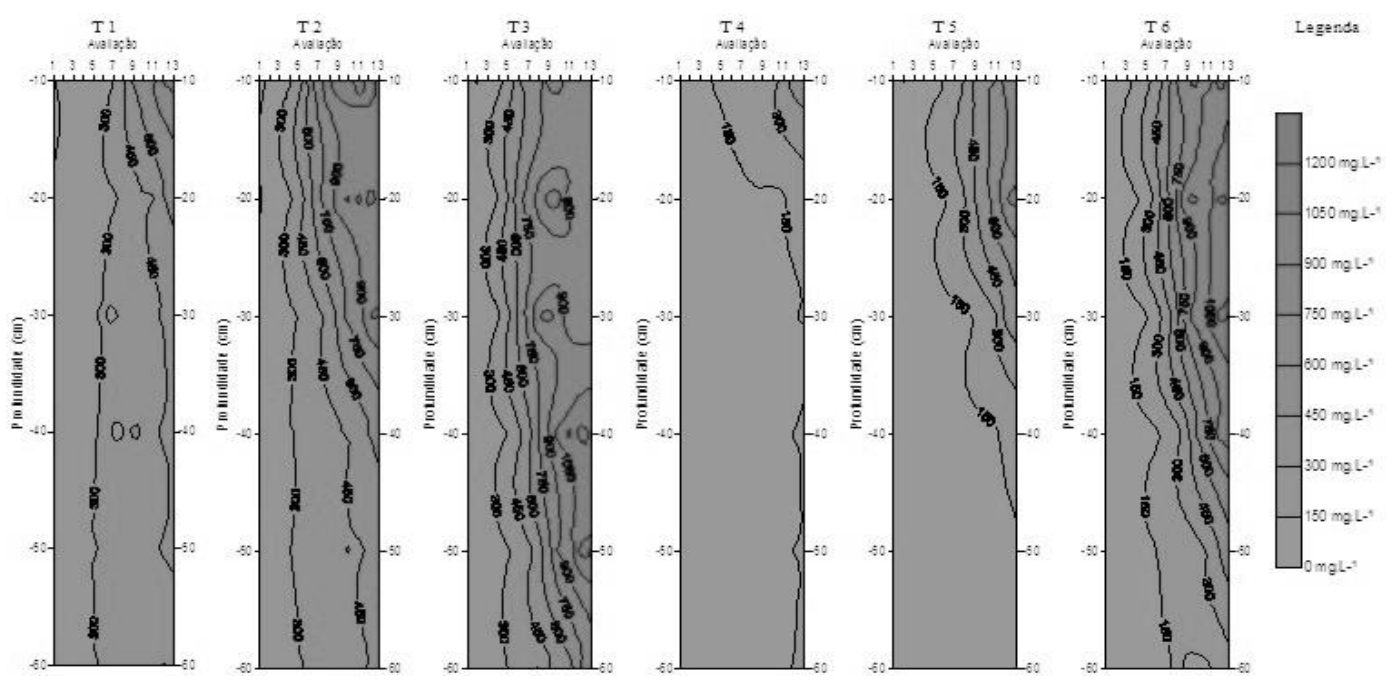

Figura 1. Distribuição espacial do íon nitrato nos 6 tratamentos para as 13 avaliações e nas seis profundidades $(0,10,0,20,0,30,0,40$ 0,50 e $0,60 \mathrm{~m})$ de amostragem.

Quanto ao íon potássio, a análise de variância mostra que todos os fatores tiveram efeito significativo sobre sua distribuição no solo, exceto a interação do tipo solo x vazão dos gotejadores $(\operatorname{Pr}>0,5)$ e a interação tripla dos fatores (Tabela 6). 
Tabela 6. ANOVA para os efeitos da textura do solo, da vazão dos gotejadores, da profundidade do solo e de suas interações sobre a distribuição do íon potássio ([K $\left.\left.{ }^{+}\right]\right)$no perfil do solo.

\begin{tabular}{ccccc}
\hline \multirow{2}{*}{ Fontes de Variação } & \multicolumn{2}{c}{ Grau de Liberdade (GL) } & \multirow{2}{*}{ F } & \multirow{2}{*}{ Pr $>$ F } \\
\cline { 2 - 4 } & Numerador & Denominador & & \\
\hline Solo & 1 & 12 & 4,93 & $<0,0464$ \\
Vazão & 2 & 12 & 27,97 & $<0,0001$ \\
Solo*Vazão & 2 & 12 & 1,35 & $<0,2961$ \\
Profundidade & 5 & 60 & 76,55 & $<0,0001$ \\
Solo* Profundidade & 5 & 60 & 4,76 & $<0,0010$ \\
Vazão* Profundidade & 10 & 60 & 12,09 & $<0,0001$ \\
Solo*Vazão* Profundidade & 10 & 60 & 1,73 & $<0,0954$ \\
\hline
\end{tabular}

Em termos de profundidade, a distribuição do potássio no solo seguiu a mesma tendência do nitrato, ficando as maiores médias concentradas nas camadas superficiais $(77,6 \mathrm{mg}$ $\mathrm{L}^{-1}$ para o solo arenoso, e 39,3 $\mathrm{mg} \mathrm{L}^{-1}$ para o solo argiloso), embora atingindo profundidades bem menores que o nitrato. Este fato está relacionado à predominância de cargas negativas na fração sólida do solo, que implica na maior retenção desse cátion, que fica mais adsorvido na matriz do solo, quando comparada ao ânion nitrato.

As concentrações do íon potássio, em mg $\mathrm{L}^{-1}$, observadas nas soluções extraídas do solo pelos extratores de solução, "leituras" numeradas no gráfico de 1 a 13, foram plotadas na forma gráfica (Figura 2) para melhor visualização dos efeitos dos tratamentos. Nesta figura pode-se perceber que as concentrações observadas ( $\mathrm{mg} \mathrm{L}^{-1}$ ) não foram muito elevadas, se comparadas com a concentração aplicada (superior a $300 \mathrm{mg} \mathrm{L}^{-1}$ de $\mathrm{K}^{+}$). Apenas nos tratamentos com maiores vazões foram observadas diferenças da concentração do íon potássio entre os solos. Neste caso, no solo arenoso foram observadas as maiores concentrações.

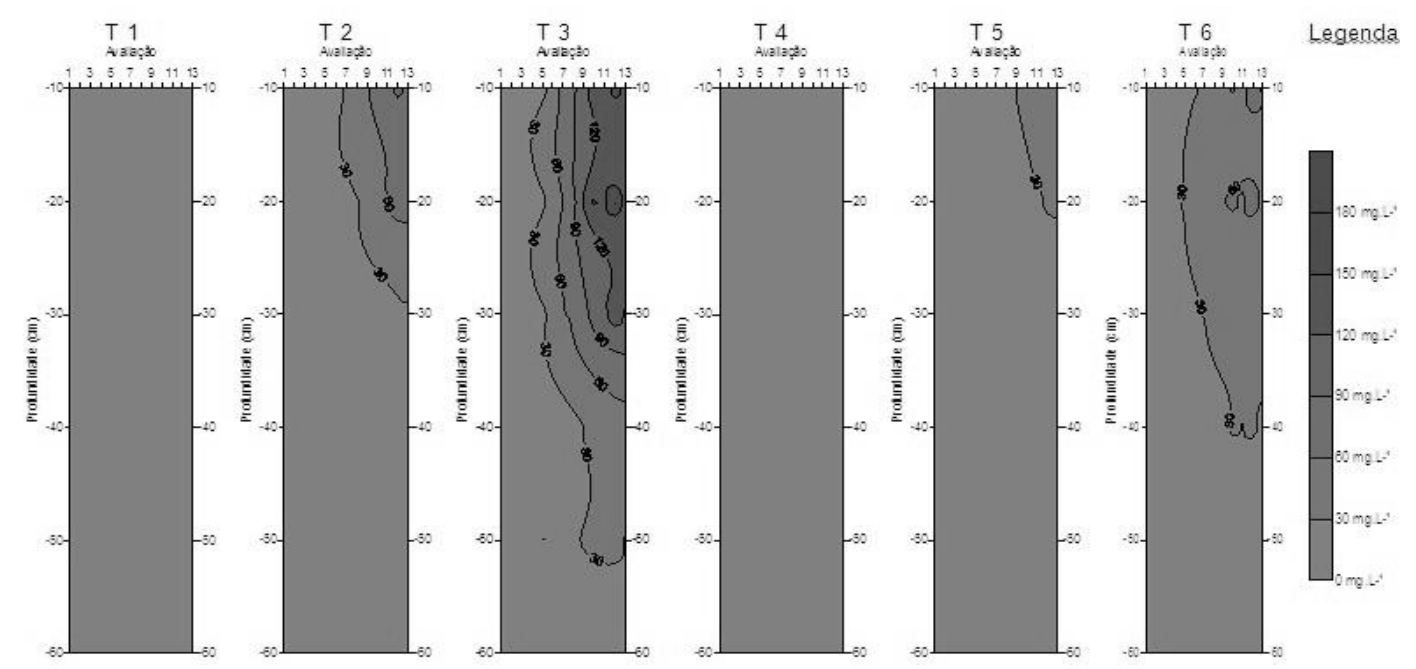

Figura 2. Distribuição espacial do íon potássio nos 6 tratamentos para as treze avaliações e nas seis profundidades $(0,10,0,20,0,30,0,400,50$ e $0,60 \mathrm{~m})$ de amostragem.

Na Tabela 7 é apresentada a análise de variância para os efeitos dos fatores principais e de suas interações, sobre a distribuição do $\mathrm{pH}$ no perfil do solo. De acordo com essa tabela, exceto a interação do tipo do tipo solo $\mathrm{x}$ profundidade, todos os fatores e interações tiveram influência (efeito significativo) sobre a distribuição do $\mathrm{pH}$ no perfil do solo, nas condições experimentadas. 
Tabela 7. ANOVA para os efeitos do solo, da vazão dos gotejadores, da profundidade do solo e de suas interações sobre o potencial de hidrogênio na solução do solo

\begin{tabular}{ccccc}
\hline \multirow{2}{*}{ Fontes de Variação } & \multicolumn{2}{c}{ Grau de Liberdade (GL) } & \multirow{2}{*}{ F } & \multirow{2}{*}{ Pr>F } \\
\cline { 2 - 4 } & Numerador & Denominador & & \\
\hline Solo & 1 & 12 & 46,21 & $<0,0001$ \\
Vazão & 2 & 12 & 24,90 & $<0,0001$ \\
Solo*Vazão & 2 & 12 & 6,94 & $<0,0099$ \\
Profundidade & 5 & 60 & 48,22 & $<0,0001$ \\
Solo* Profundidade & 5 & 60 & 1,41 & $<0,2324$ \\
Vazão* Profundidade & 10 & 60 & 10,95 & $<0,0001$ \\
Solo*Vazão* Profundidade & 10 & 60 & 11,32 & $<0,0001$ \\
\hline
\end{tabular}

Analisando-se as médias apresentadas na Tabela 8, pode-se observar que, em um nível de 5\% de significância pelo teste de Tukey, não houve diferenças estatísticas entre os valores de pH nos tratamentos com vazão de gotejamento igual a $2 \mathrm{~L} \mathrm{~h}^{-1}$, mesmo na comparação entre os dois tipos de solos (os valores ficaram próximos a 6,0). Já nos tratamentos com vazão de $4 \mathrm{~L} \mathrm{~h}^{-1}$, observa-se uma oscilação dos valores de $\mathrm{pH}$ entre 3,88 (solo arenoso, a $20 \mathrm{~cm}$ de profundidade) e 6,75 (solo argiloso, a $50 \mathrm{~cm}$ ). Para a vazão de gotejamento de $8 \mathrm{~L} \mathrm{~h}^{-1}$, o efeito ocorreu em todas as camadas no solo arenoso e praticamente em todas as camadas no solo argiloso, a exceção das duas últimas camadas que sofreram menor redução nos valores de $\mathrm{pH}$, causada pela solução de fertirrigação, que era mais ácida do que os solos.

Tabela 8. Médias dos valores de pH nos solos arenoso e argiloso, nas profundidades 10, 20, 30, 40, 50 e $60 \mathrm{~cm}$, quando submetidos a 13 aplicações sucessivas de solução de fertirrigação e com vazões de gotejadores de 2, 4 e $8 \mathrm{~L} \mathrm{~h}^{-1}$

\begin{tabular}{ccccc}
\hline \multirow{2}{*}{ Solo } & $\begin{array}{c}\text { Profundidade } \\
\text { (cm) }\end{array}$ & \multicolumn{3}{c}{ Vazão dos gotejadores $\left(\mathbf{L ~ h ~ h}^{-\mathbf{1}}\right)$} \\
\cline { 3 - 5 } & 10 & $5,38 \mathrm{Aa}$ & $4,08 \mathrm{Ea}$ & $4,11 \mathrm{CDEa}$ \\
\multirow{4}{*}{ Arenoso } & 20 & $6,06 \mathrm{Aa}$ & $3,88 \mathrm{~Eb}$ & $3,81 \mathrm{~Eb}$ \\
& 30 & $6,11 \mathrm{Aa}$ & $4,46 \mathrm{DEb}$ & $3,86 \mathrm{~Eb}$ \\
& 40 & $5,91 \mathrm{Aa}$ & $5,12 \mathrm{CDab}$ & $4,12 \mathrm{DEb}$ \\
& 50 & $5,94 \mathrm{Aa}$ & $5,25 \mathrm{BCab}$ & $4,50 \mathrm{CDEb}$ \\
& 60 & $5,89 \mathrm{Aa}$ & $5,36 \mathrm{BCa}$ & $4,87 \mathrm{BCDa}$ \\
\hline \multirow{4}{*}{ Argiloso } & 10 & $6,10 \mathrm{Aa}$ & $6,36 \mathrm{ABCa}$ & $3,98 \mathrm{~Eb}$ \\
& 20 & $6,28 \mathrm{Aa}$ & $6,44 \mathrm{ABCa}$ & $4,06 \mathrm{DEb}$ \\
& 30 & $6,36 \mathrm{Aa}$ & $6,51 \mathrm{Aba}$ & $5,20 \mathrm{BCa}$ \\
& 40 & $6,37 \mathrm{Aa}$ & $6,73 \mathrm{Aa}$ & $5,90 \mathrm{Aba}$ \\
& 50 & $6,37 \mathrm{Aa}$ & $6,75 \mathrm{Aa}$ & $6,00 \mathrm{Aa}$ \\
& 60 & $5,38 \mathrm{Aa}$ & $4,08 \mathrm{Ea}$ & $4,11 \mathrm{CDEa}$ \\
\hline
\end{tabular}

Médias seguidas pela mesma letra, minúsculas nas linhas e maiúsculas nas colunas, não diferem entre si, pelo teste de Tukey $(\mathrm{P}>0,05)$.

Quando comparados os tipos de solo, o solo arenoso apresentou menores médias de $\mathrm{pH}$ em todas as vazões de aplicação; se analisada a vazão de $8 \mathrm{~L} \mathrm{~h}^{-1}$, observa-se um maior poder de acidificação. Esse resultado já era esperado, uma vez que as soluções aplicadas tinham a mesma concentração em todos os tratamentos e, sendo o tempo de aplicação o mesmo, um maior volume foi aplicado com o gotejador de maior vazão.

A análise de variância para os efeitos das principais fontes de variação (solo, vazão e profundidade) e de suas interações sobre a distribuição da condutividade elétrica no perfil 
do solo, é apresentada na Tabela 9. De acordo essa tabela, todas as interações entre os fatores tiveram efeito significativo $(\operatorname{Pr}<0,05)$ sobre a distribuição da condutividade elétrica do solo.

Tabela 9. ANOVA para os efeitos do solo, da vazão dos gotejadores, da profundidade do solo e de suas interações sobre a condutividade elétrica (CE) da solução do solo.

\begin{tabular}{ccccc}
\hline \multirow{2}{*}{ Fontes de Variação } & \multicolumn{2}{c}{ Grau de Liberdade (GL) } & \multirow{2}{*}{ F } & \multirow{2}{*}{ Pr>F } \\
\cline { 2 - 4 } & Numerador & Denominador & & \\
\hline Solo & 1 & 12 & 102,84 & $<0,0001$ \\
Vazão & 2 & 12 & 76,92 & $<0,0001$ \\
Solo*Vazão & 2 & 12 & 6,22 & $<0,0140$ \\
Profundidade & 5 & 60 & 60,30 & $<0,0001$ \\
Solo* Profundidade & 5 & 60 & 9,97 & $<0,0001$ \\
Vazão* Profundidade & 10 & 60 & 12,73 & $<0,0001$ \\
Solo*Vazão* Profundidade & 10 & 60 & 4,99 & $<0,0001$ \\
\hline
\end{tabular}

Na Tabela 10 estão dispostos os valores médios resultantes da interação tripla entre os fatores sobre a distribuição da condutividade elétrica da solução (CE) no perfil do solo. Os valores médios encontrados na solução extraída dos solos arenoso e argiloso, foram 1,214 e $0,477 \mathrm{dS} \mathrm{m}^{-1}$ para os tratamentos com vazão igual a $2 \mathrm{~L} \mathrm{~h}^{-1} ; 1,550$ e $1,127 \mathrm{dS} \mathrm{m}^{-1}$ para os tratamentos com vazão de $4 \mathrm{~L} \mathrm{~h}^{-1}$; e 1,941 e $1,527 \mathrm{dS} \mathrm{m} \mathrm{m}^{-1}$ para os tratamentos com vazão de $8 \mathrm{~L} \quad \mathrm{~h}^{-1}$, respectivamente.
Com estes resultados, pode-se afirmar que o solo argiloso funcionou como uma espécie de "filtro", retendo todo ou pelo menos a maior parte do fertilizante aplicado, o que implicou em redução da CE na solução do solo em todas as vazões de gotejamento aplicadas, nas camadas mais profundas. Esta propriedade do solo adsorver o soluto é denominada de fator de retardamento, que depende de vários fatores, como o tipo de solo, o tipo e a concentração do soluto, dos íons acompanhantes, entre outros (RIVERA et al., 2008).

Tabela 10. Médias dos valores de condutividade elétrica $\left(\mathrm{dS} \mathrm{m}^{-1}\right)$ nos solos de textura arenosa e argilosa e nas profundidades 10, 20, 30, 40, 50 e $60 \mathrm{~cm}$, quando submetidos a 13 aplicações sucessivas de solução de fertirrigação, com vazões de 2,4 e $8 \mathrm{~L} \mathrm{~h}^{-1}$.

\begin{tabular}{ccccc}
\hline \multirow{2}{*}{ Solo } & Profundidade & \multicolumn{3}{c}{ Vazão dos gotejadores $\left(\mathbf{L ~ h}^{\mathbf{- 1}}\right)$} \\
\cline { 2 - 5 } & $(\mathbf{c m})$ & 2 & 4 & 8 \\
\hline \multirow{5}{*}{ Arenoso } & 10 & $1,925 \mathrm{Aa}$ & $2,047 \mathrm{Aa}$ & $1,781 \mathrm{Aba}$ \\
& 20 & $1,647 \mathrm{Aba}$ & $1,924 \mathrm{Aba}$ & $1,984 \mathrm{Aa}$ \\
& 30 & $1,017 \mathrm{BCa}$ & $1,849 \mathrm{Aa}$ & $1,856 \mathrm{Aba}$ \\
& 40 & $0,938 \mathrm{BCb}$ & $1,536 \mathrm{ABa}$ & $2,078 \mathrm{Aa}$ \\
& 50 & $0,883 \mathrm{BCb}$ & $1,096 \mathrm{BCb}$ & $2,011 \mathrm{Aa}$ \\
\multirow{5}{*}{ Argiloso } & 60 & $0,872 \mathrm{BCDb}$ & $0,849 \mathrm{BCb}$ & $1,934 \mathrm{Aa}$ \\
& 10 & $1,237 \mathrm{ABb}$ & $2,139 \mathrm{Aa}$ & $1,734 \mathrm{Aba}$ \\
& 20 & $0,460 \mathrm{Cb}$ & $2,038 \mathrm{Aa}$ & $1,983 \mathrm{Aa}$ \\
& 30 & $0,284 \mathrm{Ec}$ & $1,539 \mathrm{ABab}$ & $1,967 \mathrm{Aba}$ \\
& 40 & $0,311 \mathrm{Db}$ & $0,515 \mathrm{Cb}$ & $1,728 \mathrm{Aba}$ \\
& 50 & $0,286 \mathrm{~Eb}$ & $0,279 \mathrm{Db}$ & $1,167 \mathrm{Ba}$ \\
& 60 & $0,287 \mathrm{Ea}$ & $0,254 \mathrm{Da}$ & $0,583 \mathrm{Ca}$ \\
\hline
\end{tabular}

Médias seguidas pela mesma letra, minúsculas nas linhas e maiúsculas nas colunas, não diferem entre si, pelo teste de Tukey $(\mathrm{P}>0,05)$ 
Bernert et al. (2015) consideram que o pH e a condutividade elétrica são fatores importantes a serem considerados para o manejo da fertirrigação, como critérios técnicos e como base para incremento na produção da cultura.

\section{CONCLUSÕES}

A percolação dos íons nitrato e potássio é dependente do tipo de solo e da intensidade de aplicação destes nutrientes no solo.

O uso da fertirrigação por gotejamento, com taxas elevadas de aplicação, promove maior deslocamento de íons em profundidade, sendo este efeito mais intensificado nos solos de textura arenosa.

Os valores médios de $\mathrm{pH}$ da solução do solo coletados foram menores no solo arenoso quando comparados ao solo argiloso, sendo esse efeito observado com mais intensidade nas camadas superiores, o que reflete o poder acidificante da solução de fertirrigação aplicada.

O solo argiloso possui maior capacidade de reter os sais aplicados na fertirrigação que o solo arenoso, o que ocasiona menores valores médios da condutividade elétrica da solução percolada para as camadas mais profundas.

\section{REFERÊNCIAS}

ARAUZO, M.; DÍEZ, J. A.; HERNÁIZ, P. Estimación de balances hídricos y lixiviación de nitratos en sistemas agrícolas. In: ALVAREZ-BENEDÍ, J.; MARINERO, P. Estudios de La Zona No Saturada del Suelo. v. 6, Valladolid: Instituto Tecnológico Agrário, 2003. cap. 6, p. 39-44.

BERNERT, R. B.; ESCHEMBACK, V.; JADOSKI, S. M.; LIMA, A. DOS S.; POTT, C. A. Características do $\mathrm{pH}$ e condutividade elétrica no manejo de fertirrigação. Brazilian Journal of Applied Technology for Agricultural Science, v.8, p.80-87, 2015.

CAMEIRA, M. R.; PEREIRA, A.; AHUJA, L., MA, L. Sustainability and environmental assessment of fertigation in an intensive olive grove under Mediterranean conditions. Agricultural Water Management, v. 146, p. 346-360, 2014.

CARVALHO, N. L. DE; ZABOT, V. Nitrogênio: nutriente ou poluente? Revista Eletrônica em Gestão, Educação e Tecnologia Ambiental, v. 6, n. 6, p. 960-974, 2012.

DIAS, N. DA S.; DUARTE, S. N.; GHEYI, H. R.; MEDEIROS, J. F. DE; SOARES, T. M. Manejo da fertirrigação e controle da salinidade do solo sob ambiente protegido, utilizando-se extratores de solução do solo. Revista Brasileira de Engenharia Agrícola e Ambiental, v. 9, n. 4, p. 496-504, 2005.

DUENHAS, L. H.; VILLAS BÔAS, R. L.; SOUZA, C. M. P. DE; RAGOZO, C. R. A.; BULL, L. T. Fertirrigação com diferentes doses de NPK e seus efeitos sobre a produção e qualidade de frutos de laranja (Citrus sinensis O.) 'Valência'. Revista Brasileira de Fruticultura, v. 24, n. 1, p. 214-218, 2002.

MACHADO, C. C.; PRATA NETO, I.; COELHO, R. D. Consumo de soluções de fertilizantes em plantas adultas de lima ácida 'Tahiti' sobre limão 'Cravo' nas condições de irrigação localizada. Irriga, v. 9, n. 3, p. 235247, 2004.

MARQUES, J. D. DE O.; LUIZÃO, F. J.; TEIXEIRA, W. G.; FERREIRA, S. J. F. Variações do carbono orgânico dissolvido e de atributos físicos do solo sob diferentes sistemas de uso da terra na Amazônia Central. Revista Brasileira de Ciência do Solo, v. 36, n. 2, p. 611-622, 2012.

MEDEIROS, P. R. F.; DUARTE, S.N.; UYEDA, C. A.; SILVA, E. F. e; M., J. F. Tolerância da cultura do tomate à salinidade do solo em ambiente protegido. Revista Brasileira de Engenharia Agrícola e Ambiental (Online), Campina Grande, v. 16, p. 51-55, 2012.

MIRANDA, J. H. de; BERGAMO, L. R.; REIS, J. B. R. S.; CRUCIANI, D. E.; DUARTE, S. N. 
Distribuição da concentração de potássio no solo em lisímetros cultivados com amendoim. Engenharia Agrícola, Jaboticabal, v. 30, p. 253-263, 2010.

OLIVEIRA, F. DE A. DE; MEDEIROS, J. F. DE; DUARTE, S.N.; SILVA JÚNIOR, M. J. DA; CAMPELO, C.M. Calibração de extratores providos de cápsula porosa para monitoramento da salinidade e da concentração de íons. Engenharia Agrícola, v. 31, n.3, p.520-528, 2011.

OLIVEIRA, F. DE A. DE; DUARTE, F. N.; MEDEIROS, J. F. DE; DIAS, N. DA S.; OLIVEIRA, M. K. T.; SILVA, R. C. P.; LIMA, K. S. Nutrição mineral do pimentão submetido a diferentes manejos de fertirrigação. Horticultura Brasileira, v. 33, n. 2, p. 216-223, 2015.

RIVERA, R. N. C.; MIRANDA, J. H.; DUARTE, S. N.; BOTREL, T. A. Modelo aplicado à dinâmica da água e do potássio no solo sob irrigação por gotejamento: Análise de sensibilidade. Engenharia

Agrícola, Jaboticabal, v. 28, p. 448-459, 2008.

SAS INSTITUTE. SAS/STAT software 9.1. Cary, 2003.
SILVA E. M. DA; LIMA, C. J. G. DE S.; DUARTE, S. N.; BARBOSA, F. DA S.; MASCHIO, R. Níveis de salinidade e manejo da fertirrigação sobre características da berinjela cultivada em ambiente protegido. Revista Ciência Agronômica, v. 44, n. 1, p. 150-158, 2013.

SILVA JÚNIOR, M. J. DA; DUARTE, S. N.; OLIVEIRA, F. DE A. DE; MEDEIROS, J. F. DE; DUTRA, I. Resposta do meloeiro à fertigação controlada através de íons da solução do solo: Desenvolvimento vegetativo. Revista Brasileira de Engenharia Agrícola e Ambiental, v. 14, n. 7, p. 715-722, 2010.

SOUZA, E. R. DE; MELO, H. F. DE; ALMEIDA, B. G. DE; MELO, D. V. M. DE. Comparação de métodos de extração da solução do solo. Revista Brasileira de Engenharia Agrícola e Ambiental, v. 17, n. 5, p. 510-517, 2013.

YANG, J. E.; KIM, J. J.; SKOGLEY, E. O.; SCHAFF, B. E. A simple spectrophotometric determination of nitrate in water, resin and soil extracts. Soil Science Society of America Journal, v. 62, n. 4, p. 1108-1115, 1998. 